\title{
Brand Association and Emotional \\ Confidence: Determinants of Brand \\ Loyalty: An Abstract
}

\author{
Wajid Hussain Rizvi, Amber Gul Rashid, and Huma Amir
}

\begin{abstract}
Brand loyalty has been at the heart of marketing strategy as one of the key factors that drive revenues and success of a brand. Consumers' emotional connection with a brand is considered key to assess strength of loyalty for long-term sustainability of a brand. Affective certainty toward a brand as a result of brand experience can lead to brand loyalty. This paper investigates influence of emotional confidence and brand association on brand loyalty. Further, it investigates whether there is statistically significant difference between consumers having low emotional confidence and those showing high emotional confidence in terms of their brand loyalty.

Data was collected outside fast-food restaurants across Karachi, using systematic sampling. Every fourth person exiting the restaurant was approached to fill a questionnaire $(n=252)$. The data was analyzed using structural equation modeling. The results suggest that both brand association $(\beta=.72 P<.001)$ and emotional confidence $(\beta=.19 P<.001)$ have statistically significant influence on brand loyalty. The variance explained in brand loyalty was higher when emotional confidence was included in the model. Independent-samples test suggests statistically significant difference $(t(250)=-6.99, P<.001)$ between consumers having low emotional confidence and those having high emotional confidence in terms of their brand loyalty. Consumers with higher emotional confidence showed higher brand loyalty.
\end{abstract}

W. H. Rizvi · A. G. Rashid $\cdot$ H. Amir (ه)

Institute of Business Administration, Karachi, Sindh, Pakistan

e-mail: wrizvi@iba.edu.pk; arashid@iba.edu.pk; hamir@iba.edu.pk 